\title{
LA CIVILIZACIÓN DEL ENCIERRO
}

Javier Meza*

En el siglo XVI, el desarrollo del saber médico no va unido a la sustitución de lo sobrenatural por lo patológico, sino a la aparición de los poderes transgresivos del cuerpo y de la imaginación. Médicos como Molitor o Weyer no pudieron naturalizar lo demoníaco bajo la forma de la enfermedad; hicieron del demonio el sutil médico capaz de doblegar el cuerpo a sus astucias y de imponerle la falsa imagen de sus poderes. Tendremos la prueba en el siglo XVI, cuando en el internamiento se haga padecer el mismo tipo de exclusión a los visionarios, fanáticos, insensatos, a todos los que imaginan y se equivocan.

Michel Foucault

to creciente en todos los ámbitos" para mejorar a las sociedades, la civilización occidental siempre ha buscado "el acrecentamiento del poder y el orden mismo". ${ }^{1}$ Educados para contemplar la historia como permanente evolución y, por lo mismo, irrepetible, negamos la persistencia de actitudes culturales que sobreviven de una época a otra. No obstante, es posible reconocer una continuidad reproductiva en el nivel de la búsqueda de técnicas de sometimiento. Búsqueda recurrente e

* Departamento Académico de Estudios Generales, ITAM.

${ }^{1}$ Dreyfus Hubert L. y Rabinow, Paul, Michel Foucault: más allá del estructuralismo y la hermenéutica, 1988, México, UNAM, p. 21. 
Javier Meza

incesante, desarrollada por el poder en diferentes caminos que cuando se encuentran o convergen acostumbran intercambiar entre sí sus experiencias.

El poder que constriñe, aglutina y da forma a las sociedades siempre ha pretextado buscar al mal para aniquilarlo. El mal, pretendidamente se genera y se encuentra más allá del límite que el orden impone como permitido: extra vas debitum (fuera del vaso debido). Al dividir, por medio de ciertos gestos, el propio orden genera un límite que en sí mismo invita a la transgresión, y a la que normalmente se responde con el castigo. En Occidente los gestos que crean los límites o las fronteras varían, pues diversos son los rostros del poder y diferentes las resistencias contra él. Los gestos y las fronteras del poder religioso y laico del mundo europeo durante los siglos XV, XVI y XVII constituyen un conjunto de procesos alrededor de palabras claves como hereje, leproso, bruja y loco, caracterizados por aprendizajes, oposiciones, mezclas, reciclajes entre poderes diferentes, que determinan y definen a la autoridad del mundo moderno.

Las pretensiones imperialistas de la Iglesia católica se originan en un acto de fe, pero sobre todo en la fuerza. El acto de fe plantea que Cristo, como pater familias y amo del mundo, convirtió al Papa en su vicario, y por consiguiente éste tiene poder absoluto sobre todos los seres, no importa que sean cristianos o infieles. ${ }^{2}$ Guiada por esta idea totalitaria desarrolló diferentes términos relacionados con la situación de límite: cisma, apostasía, simonía, secta, judaísmo, brujería, entre otros. Sin embargo, todos ellos fueron contenidos en un solo concepto: herejía. La herejía es una elección contraria, discrepante. Rechaza total o parcialmente los códigos, creencias, ideas, gestos que integran y configuran el

${ }^{2}$ La Iglesia también justificó su desmedida sed de poder mediante la llamada Donación de Constantino, documento jurídico en donde supuestamente en los inicios de la Iglesia el emperador Constantino legó a Silvestre, Obispo de Roma, el dominio sobre los cuatro patriarcados imperiales y el Imperio de Occidente. La Iglesia lo usó durante la Edad Media, sobre todo en su esfuerzo por someter al poder temporal; finalmente, en el Renacimiento el humanista Lorenzo Valla demostró que la Donación era un documento falso, y cuestionó las pretensiones del papado al dominio temporal. Ver Skinner, Quentin, Los fundamentos del pensamiento político moderno. I. el Renacimiento, México, F.C.E., 2 T, p. 228, T. I. 


\section{LA CIVILIZACIÓN DEL ENCIERRO}

círculo de lo permitido. La herejía necesita imaginación; hay herejes que sólo rechazan sin proponer nada a cambio (lo que es raro), otros buscan imponer las viejas ideas (ortodoxia contra heterodoxia), o bien, proponen una corrección innovadora. ${ }^{3} \mathrm{La}$ herejía, para las voces representativas de la autoridad eclesiástica, era toda opinión o acto pertinax, individual o colectivo, en contra de la "verdadera fe", pues la herejía (elección), por su pertinacia se convertía en impertinente. Durante la Edad Media la herejía se asoció al daño físico y a la enfermedad, porque el criterio religioso poseía desviaciones médicas, y se le consideró una insanía contagiosa. Así, tanto a la lepra como a la locura se les vio como un castigo producido por la herejía: el leproso y el loco lo eran por sus actos y pensamientos inmorales. Al temer el contagio de la lepra, de los actos y pensamientos prohibidos, se encerraba a los sujetos o por lo menos se les expulsaba lejos. Asimismo, al hereje pertinax se le excomulgaba porque la excomunión tuvo el rango de pena medicinal, y cuando la pertinacitas cedía automáticamente el hereje sanaba. ${ }^{4}$

La Iglesia siempre recurrió a la exclusión y al rechazo para defender su autoritarismo: antes que convencer prefirió vencer. Sus victorias se cimentaron en el interrogatorio y persecución de las elecciones contrarias o herejías. Esta obsesión dio paso a la formación de una institución encargada de vigilar y perseguir organizadamente a los sospechosos de disentir. Ella fue la Inquisición, cuya institucionalización se debió al Concilio de Letrán (1215), y se creó para destruir a la herejía albigense. La inquisitio haereticae pravitatis o Inquisición (búsqueda) de la perversidad herética desarrolló un sistema caracterizado por la vigilancia, la concentración, el encierro, la exclusión y el castigo. Con el invento de la confesión la Iglesia introdujo en el sujeto la conciencia (idea del yo) y el sentimiento de culpa; y fue la piedra angular que mantuvo el funcionamiento casi perfecto de la Inquisición. La confesión abría el camino para denunciarse a sí mismo y a otros —quizá más a los otros. Para denunciarse y denunciar siempre fue necesaria la vigilancia porque para la Iglesia todos eran culpables, y sólo sus jueces podían declarar lo contrario. En

${ }^{3}$ Chenu, M.D., "Ortodoxia y herejía. El punto de vista del teólogo" en Herejías y sociedades en la Europa preindustrial. Siglos XI-XVIII, comp. dé Jacques Le Goff, S. XXI, Madrid, 1987, p. 3 y 4.

${ }^{4}$ Op. cit., p. 7. 
el principio la institución no fue permanente, pues luego de perseguir y exterminar a la herejía desaparecía junto con ella, y quedaba prácticamente en estado latente; tuvo que esperar hasta el reinado de los Reyes Católicos, Isabel de Castilla y Fernando de Aragón, para convertirse en un Consejo de Estado permanente (1483) al lado de los otro cuatro grandes Consejos: Estado, Finanzas, Castilla y Aragón. Establecida con el pretexto de perseguir a las herejías judía y musulmana, sirvió sobre todo al centralismo monárquico porque con su labor lenta, paciente, siempre vigilante, logró imponer creencias y comportamientos homogéneos a los gobernados. En efecto, el tribunal fue el perro guardián de la fe (dominicane), pero también una eficiente y feroz policía encargada del control social; se calcula que entre 1480 y 1484 sólo existían 10 tribunales en la península española, sin embargo, para 1495 su número ya ascendía a 25 . En su forma de actuar sobresalían dos aspectos: una terrible obsesión por la verdad, que determinaba los agudos métodos de análisis para conocer las ideas de los prisioneros (proceso de búsqueda hoy presente en la policía moderna: soplones, interrogatorios de lo general a lo particular, tortura, dilación del proceso, etc.) y la reclusión temporal para inculcar en los acusados un dócil sometimiento basado en los sentimientos de culpa.

La obsesión por la búsqueda fue una actitud muy difundida durante el Renacimiento. En este período la razón, el sueño, lo irrazonable corrían buscando el exceso de sentido, la abundancia de representaciones, las equivalencias imaginarias. Precisamente en la liberación y desbordamiento de la imaginación, en la proliferación de ideas (excesos del sentido) el Renacimiento erigió su grandeza. A juicio de Foucault, por ejemplo, el lenguaje y la pintura transitaban por caminos diferentes y cada uno, como métodos de expresión seguía y buscaba experiencias distintas. También el desorden y la locura aparecían realizando "una sorda invasión" generalizada. Una locura que desde los inicios del Renacimiento reposaba latente "en las ruinas del simbolismo gótico", rico en significaciones espirituales representadas casi siempre en formas fantásticas y atrevidas. La liberación renacentista basada en "la abundancia de significaciones" y sentidos en todas direcciones permitió que las relaciones entre las cosas se convirtiesen en "numerosas, entretejidas", copiosas, "sólo descifradas por el esoterismo del saber", pues estaban "sobrecargadas de atributos, indicios, alusiones", al grado que su propia 


\section{LA CIVILIZACIÓN DEL ENCIERRO}

faz se borraba. ${ }^{5}$ La situación de la locura es la que mejor ilustra las condiciones de esta época. Por un lado había tantas locuras como cabezas, y a los locos se les embarcaba en naves para que recorriendo las aguas encontrasen su razón. La locura corría sobre el agua, se disolvía en ella: eran barcos ebrios buscando el infinito, lo abierto, lo desconocido, lo extraño, el sinfín: Del mundo cerrado al infinito universo (Giordano Bruno). Según Foucault, para el hombre renacentista la locura representó una tentación atractiva y un recurso para la crítica expresada por medio de la sátira moral, porque reunía la experiencia cósmica y trágica y la experiencia crítica y reflexiva. Experiencias que después se escindirían "abriendo en la unidad profunda de la locura una brecha que nunca volverá a colmarse". 6 Luego del Renacimiento el discurso de la conciencia crítica desplazó a la experiencia trágica: la razón neutralizó y desterró la locura. Precisamente a fines del siglo XVI y principios del XVII uno de los juegos de la sociedad barroca consistió en cazar a la locura y derrotarla, marcando con esto el inicio de la época moderna. En el barroco, la locura trágica que antes llevaba al desgarramiento absoluto y a la muerte, evita este final y se convierte sólo en un punto intermedio: ya es un simple obstáculo, es "nudo y no desenlace", "peripecia y no final". Ahora su presencia sólo es un medio que permite y garantiza crear la nueva verdad y la nueva razón. ${ }^{7}$ Verdad y razón de una civilización sacudida por la diversidad de sentidos y significados a consecuencia de la paulatina desaparición de un viejo orden social y el surgimiento del capitalismo.

En este panorama sobresale el hambre, la miseria, pero también el encierro. El hambre sólo desapareció de Occidente hacia fines del siglo XVIII; en los dos siglos anteriores - a finales del XVI y sobre todo en el XVII- para enfrentar las amenazas de los ejércitos de pobres el poder aristocrático y el burgués, la Iglesia y los ricos implantaron feroces medidas. El Estado español moderno (siglo XV) empleó la Inquisición y el internamiento temporal del hereje, ya para reeducarlo o bicn para condenarlo a la hoguera. La Época Clásica recurrió al "encierro genera-

5 Foucault, Michel, Historia de la locura en la Época Clásica, 1979 México, F.C.E., T. I., p. 35.

6 Op. cit., p. 4.

7 Op. cit., p. 70 s. 
Javier Meza

lizado" para implantar en el sujeto nuevos valores, fincados en la reivindicación del trabajo y el rechazo de la pobreza. ${ }^{8}$

En Francia, por ejemplo, el Hospital General (1656) surgió más bien como una institución administrativa que medica. Constituía una instancia del nuevo orden monárquico y burgués, cuyos directores tenían “...todo poder de autoridad, de dirección, de administración, de comercio, de policía, de jurisdicción, de corrección y de sanción, sobre los pobres de París, tanto dentro como fuera del Hospital General". 9 Los directores prácticamente tenían una autonomía casi absoluta, pues no existía apelación alguna ante sus decisiones, y ni siquiera los tribunales podían intervenir. Al igual que la Inquisición española, que se extendió rápidamente por decreto real del 16 de junio de 1676 , también los hospitales se establecieron por todo el reino, aunque muchos de ellos ya existían desde principios de siglo. Estos hospitales, al igual que todas las casas de internamiento de países como Inglaterra y Alemania, obedecían sobre todo al viejo afán propio del poder de imponer orden en el mundo. La pobreza era uno de los principales obstáculos para estas aspiraciones: un nuevo orden basado en la producción incesante necesita tanto de trabajadores como de compradores. Y en esta moda ni siquiera la Iglesia podía quedarse atrás: si antes había santificado la pobreza ahora era necesario condenarla. Con el típico oportunismo que la caracteriza

8 "En París, los enfermos e inválidos fueron desde siempre conducidos a los hospitales, mientras que los válidos eran empleados en el duro y fastidioso trabajo de la interminable limpieza de los fosos de la ciudad encadenados de dos en dos. En Inglaterra, desde finales del reinado de Isabel I, aparecieron las poor laws, en definitiva leyes contra los pobres. Poco a poco se fueron multiplicando, a través de todo Occidente, las casas para pobres e indeseables, donde el internado era condenado a trabajos forzados, en las workhouses, lo mismo que en las Zuchthauser, o en las maisons de forcé, por ejemplo, ese conjunto de semicárceles que reunió bajo su administración el Gran Hospital de París, fundado en 1656. Este 'gran encierro' de los pobres, de los locos, de los delincuentes, de los hijos de familia a quienes sus padres colocaban de esta forma bajo vigilancia es uno de los aspectos psicológicos de la sociedad razonable, implacable también en su razón, del siglo XVII". Braudel, Fernand, Civilización material y capitalismo, 1974, Barcelona, Editorial Labor, p. 62.

${ }^{9}$ Ver el artículo XI del reglamento del Hospital General, citado por Michel Foucault, op. cit., p. 81. 


\section{LA CIVILIZACIÓN DEL ENCIERRO}

también participó en el nuevo internamiento, práctica que para ella no era totalmente desconocida. Como antes señalamos, el internamiento inquisitorial era temporal, pero al igual que el del Hospital General y el de las Casas de trabajo, siempre buscó reeducar al individuo y controlar su conciencia mediante una moral impuesta por el castigo y el terror. Al nuevo internamiento lo justificó con una lógica que, como siempre, no permitía escapatoria alguna a la víctima. Según su nuevo discurso, al pobre se le debía encerrar para educarlo: si el sujeto lo aceptaba mansamente, entonces era bueno, en caso contrario, malo, y por lo mismo había que encerrarlo. Para esta lógica perversa, la pobreza primera "acepta el internamiento y encuentra en él su reposo; la segunda lo rechaza, y en consecuencia lo merece". 10

Esta lógica, que no admite reclamo ni apelación, fue utilizada durante la Época Clásica por el poder religioso y el civil, pero además de aplicarse al sometido también se introdujo en las disputas libradas entre los diferentes poderes para conseguir el control social. Los argumentos y las tácticas se intercambian y los viejos y nuevos discursos parecen confundirse, como posiblemente ocurre siempre que se construyen nuevas categorías culturales.

Desde el Renacimiento el poder de la Iglesia fue retrocediendo ante las nuevas transformaciones político-estatales, económicas, y culturales. Por eso sus viejas técnicas de control y dominio fueron readaptadas y puestas al día. Durante esta época la figura del diablo suscitó abundantes reflexiones en el seno de la Iglesia, y asimismo surgió un marcado interés por las brujas. Desde 1484 Inocencio VIII "con la bula Summis desiderantes affectibus, había autorizado a los inquisidores dominicos Heinrich Institor y Jakob Sprenger a perseguir la brujería, y dos años después veía la luz la summa de la deontología que fue el Malleus Maleficarum". ${ }^{11} \mathrm{~A}$ finales del siglo XVI este texto desató diferentes polémicas entre inquisidores y médicos. Para los autores del Malleus el viejo canon Episcopi (Graciano, Decreto, II, 20, 5, 12), al plantear que ninguna criatura tenía poder para transformarse "en otra mejor o peor", y que en el mundo no existían efectos mágicos provocados por los demonios, pues sino el

${ }^{10}$ Op. cit., p. 97.

${ }^{11}$ Bertelli, Sergio, Rebeldes, libertinos yortodoxos en el barroco, 1984, Barcelona, Península, p. 43. 
Javier Meza

mundo perecería, provocaba sobre todo dos graves errores: 1) creer que no hay maleficios en el mundo, y que éstos sólo existen en la opinión de quienes acusan a los magos de ser responsables de ellos, o bien 2) aceptar que existen brujas y que el demonio es su cómplice, pero mirar sus efectos maléficos sólo como imaginarios o fantásticos. Para los inquisidores lo anterior era manifiestamente herético pues, según decían, los maleficios en el mundo "eran reales y no fantásticos". 12 Jean Weyer, médico del duque de Cleves y posiblemente inspirado en el canon Episcopi, en su De Praestigiis Daemonum (1563), sin dudar de la existencia del diablo, discrepó de que éste pudiese transformar el medio físico o el orden natural porque a su juicio sólo tenía poder sobre el alma y no sobre el cuerpo. Incapaz de influir en el mundo real, buscaba influir en los límites del alma que para Weyer se encontraba en los sentidos, en los nervios y en los humores; y su objetivo lo alcanzaba introduciéndose en la imaginación, porque además de ser diabólica, ella se encontraba justo entre el cuerpo y el alma. Así, el diablo influía sobre todo a los espíritus débiles o frágiles, y por eso sus víctimas principales eran mujeres, melancólicos, viejos, insensatos (frenéticos y borrachos) a quienes por medio de ilusiones los engañaba al hacerlos creer que él era capaz de transformar la naturaleza. Sin embargo, los espíritus fuertes e incrédulos también eran sus víctimas, pues éstos, al dudar de su existencia, sólo obedecían a otra ilusión provocada igualmente por el diablo. Esto es, tanto la credulidad como la incredulidad eran obra del demonio y demostraban su existencia. Pero lo mismo hacía la enfermedad, pues según Weyer el diablo mediante las ilusiones era capaz de provocar melancolía y enfermar el cuerpo. De esta manera, Weyer transformaba su saber "en un saber médico con desviaciones religiosas". Y así, como antes el inquisidor era una conciencia religiosa con pretensiones médicas, ahora era el médico quien recurría a formas religiosas. Por lo visto, en el Renacimiento la tragedia y la razón empezaron a separarse de la locura, pero también la moral católica y la medicina empezaron a unificarse para construir la sociedad moderna bajo la guía del médico. ${ }^{13}$

${ }^{12}$ Ver de Kraemer \& Sprenger, El martillo de las brujas. Para golpear a las brijas y sus herejías con poderosa masa, 1976 Madrid, Felmar, p. 36s.

${ }^{13}$ Foucault, Michel, "Las desviaciones religiosas y el saber médico", en Herejias y sociedades en la Europa preindustrial. Siglos XIXVIII,... op. cit., p. 913. 


\section{LA CIVILIZACIÓN DEL ENCIERRO}

El inicio de la polémica entre inquisidores y médicos fue el anuncio de la gestación y pronta aparición de nuevos gestos y límites de exclusión. El campo de batalla lo constituyó principalmente la feroz persecución desatada durante los siglos XVI y XVII por los poderes religiosos y civiles contra hombres y mujeres (sobre todo mujeres) acusadas de brujería y de tener pacto con el diablo. En 1571 una bruja le dijo a Carlos IX en Francia que tan sólo en su reino existían más de 300 000, y según el demoniólogo Henri Boguet, hacia 1602 calculaba que en toda Europa había cerca de dos millones. ${ }^{14}$ El demonio y la bruja ocupaban un lugar de primera magnitud incluso en la mente de la gente más inteligente de la época. Jean Bodin, por ejemplo, en su Demonomanie des Sorciers (1580) deseaba quemar a todas las brujas de una sola vez. Este fenómeno paneuropeo se enmarca dentro de un turbulento clima social caracterizado por un fuerte descenso en el nivel de vida, desempleo, inflación, pestes, guerras, donde la bruja apareció como la causa de todos los males. Esto es, ella fue uno de los principales chivos expiatorios de una civilización en crisis y recomposición. La credulidad en su figura por parte de las masas miserables y analfabetas es explicable: la bruja casi siempre era una vieja, pobre, indefensa y sobre todo curandera, partera, y relacionada con los viejos cultos populares, donde muchas veces están presentes drogas y plantas analgésicas que explican las alucinaciones o visiones fantásticas. Pero la aceptación de su figura por parte de los poderes establecidos nos habla más bien de una conveniencia fríamente calculada. Prueba de ello, sin duda, son las increíbles confesiones presentes en los procesos inquisitoriales, que obedecen a las amenazas y torturas aplicadas por los interrogadores para escuchar lo que ellos querían oír. Pero un mejor ejemplo de la credulidad por conveniencia lo constituye el momento histórico en donde, como en una novela, los personajes principales de la Iglesia católica como el hereje, el diablo y la bruja fueron desplazados por el poder civil y sus locos.

Para explicar los motivos de las furiosas persecuciones y procesos realizados contra la brujería en Francia durante el siglo XVII se han utilizado diferentes argumentos. Uno de los principales encontraba la causa en la contrarreforma y en el regreso de la Iglesia católica, pues

${ }^{14}$ Ver de Levack, Brian P., "La bruja" en El hombre barroco, Rosario Villari y otros, 1992, Madrid, Alianza, p. 289-318. 
Javier Meza

gracias a aquélla, ésta nuevamente se imponía a la justicia civil e implantaba otra vez sus creencias y su control social basado en la superstición. Sin embargo, para Michel Foucault la explicación más bien hay que buscarla en los conflictos ocurridos entre la Iglesia y los tribunales civiles a finales del XVI y principios del XVII. ${ }^{15}$ En un principio los tribunales civiles franceses, para desafiar a la Iglesia, rechazaban las fantásticas confesiones de los procesados por brujería y por tener pacto con el diablo. A los testimonios de los infelices dando cuentas de sortilegios y crímenes cometidos sobre todo con niños, los rechazaban por insólitos, y al acusado lo consideraban como loco o idiota, más necesitado do lástima que de mortificación. No obstante, en un momento determinado de la caza de brujas los papeles se invirtieron: ahora era la Iglesia quien dudaba de las disparatadas declaraciones de los procesados, y en cambio los tribunales civiles aceptaban todas las confesiones con una sospechosa credulidad.

La respuesta a la nueva situación era demasiado simple: atrás de ella se encontraba una táctica de la Razón de Estado. Ahora, en la mayoría de los procesos de brujería efectuados durante el siglo XVII aparecía una nueva víctima: el sacerdote. El antiguo verdugo ya era mártir, y la causa es obvia: el moderno poder civil aniquilaba mediante estos nuevos procesos "el aspecto sagrado del sacerdote". Pues la investidura sagrada y mágica del sacerdote, pacientemente construida por la Iglesia a lo largo de la Edad Media y el Renacimiento, ahora resultaba un estorbo para el nuevo control social. En otras palabras, mediante su desacralizacion se destruía el poder y la influencia que la Iglesia ejercía sobre los gobernados, utilizando en cierta forma los mismos mitos y recursos que ella empleó para consolidarse. Es indudable, la impunidad de los funcionarios garantiza la sacralidad del poder, y la Iglesia lo sabía muy bien. Por eso rehusaba juzgar a sus inquisidores, y a pesar de aceptar que se debía castigar a los sacerdotes que incurrían en faltas graves, recomendaba: "No hay que ser muy celoso en perseguir a religiosos y sacerdotes, pues el proceso de un sacerdote siempre puede interpretarse como proceso a todo el clero. El inquisidor recordará, por lo tanto, que los laicos no

${ }^{15}$ Foucault, Michel, "Médicos, jueces y brujos en el siglo XVII", en La vida de los hombres infames, 1990, Madrid, Ed. de la Piqueta, p. 25-46. 


\section{LA CIVILIZACIÓN DEL ENCIERRO}

soportan los privilegios de los eclesiásticos y que no hay nada que les alboroce tanto como los pecados de los sacerdotes y su castigo."16

Pero el conflicto entre la Iglesia y los tribunales civiles también involucraba a un tercero en discordia, que era ya el poder más importante: el rey. Éste, para centralizar el control sobre la sociedad requería sobre todo dos cosas: someter a la Iglesia y destruir la autonomía de los tribunales civiles. En un principio los tribunales civiles, que ya contaban con las simpatías de las órdenes regulares de la Iglesia, en su lucha buscaron obtener el apoyo de la corona, intentando convencerla de la conveniencia de castigar la brujería por los desórdenes sociales que provocaba, que impedían la organización de la sociedad por el Estado. Asimismo, justificaban el castigo contra ella no porque sus conjuros efectivamente se cumpliesen, sino simplemente por el hecho de desear o pensar hacer daño. No obstante, la corona no apoyó a los tribunales civiles y se inclinó por defender al clero secular, pues al actuar así a la vez que sometía a la Iglesia despojaba de toda autonomía a los tribunales y les arrebataba lo más importante para cualquier poder: el derecho a castigar. Y a éste la corona lo obtuvo plenamente mediante el establecimiento del Hospital General, institución que por decisión real adquirió el derecho absoluto a castigar todo comportamiento extraño y transgresivo. Desde estos momentos el hereje, la bruja, el enfermo, el pobre, el fanático, fueron castigados con el encierro, y así quien ahora castigaba ya no era la Iglesia sino el Estado moderno, con lo que la herejía y la brujería se secularizaban, además de que de esta manera prácticamente se institucionalizaba la persecución iniciada por Weyer contra el cuerpo y la imaginación. Ahora la brujería "es ya únicamente considerada en relación al orden del Estado moderno: la eficacia de la operación es negada, pero no la intención que implica, ni tampoco el desorden que suscita. El ámbito de su realidad se ha transferido a un mundo moral y social". 17

${ }^{16}$ Acerca de los inquisidores explícitamente indicaba que: "Aunque, recordemos que según Santo Tomás..., más vale no castigar a los inquisidores, pues castigándoles es la institución inquisitorial la que sufre los efectos y a poco ya no sería respetada ni temida por la plebe imbécil (a populo stulto)", Eimeric, Nicolau, y Pena, Francisco, El manual de los inquisidores, Introduccion y notas de Luis SalaMolins, 1983, Barcelona, Muchnik, p. 228.

${ }^{17}$ Foucault, Michel, "Médicos, jueces y brujos en el siglo XVII",... op. cit. p. 41. 


\section{Javier Meza}

Igualmente la persecución de la brujería fue sustituida por la persecución de la locura mediante el siguiente pretexto. Como el castigo de la brujería correspondía a los tribunales, para despojarlos de ese derecho la corona apeló a un argumento contundente que existía en el derecho romano. Para éste, el loco, por su imbecilidad, era un sujeto "inaccesible a la pena". Por lo tanto, convirtiendo al brujo en loco se le arrancaba el sujeto a los tribunales, y la corona automáticamente adquiría el derecho a encerrarlo sin necesidad de juicio alguno. Así, la persecución nunca cesó: el calificativo de loco permitió anular en su totalidad la conciencia del otro, y a la vez justificar el castigo del encierro como remedio curativo. 